УдК 332.1

ДОНИЧЕВ ОЛЕГ АЛЕКСАНДРОВИЧ

д.э.н., профессор, заведующий кафедрой «Экономика и управление инвестичиями и инновациями» Владимирского государственного университета имени Александра Григорьевича и Николая Григорьевича Столетовых, г. Владимир, e-mail:donoa@vlsu.com

ГРАЧЕВ СЕРГЕЙ АЛЕКСАНДРОВИЧ

к.э.н., доцент кафедры «Экономика и управление инвестиииями и инновациями» Владимирского государственного университета имени Александра Григорьевича и Николая Григорьевича Столетовых, г. Владимир, e-mail: grachev-sa@yandex.ru

\title{
ЦИФРОВЫЕ ТЕХНОЛОГИИ В ФОРМИРОВАНИИ ИННОВАЦИОННОЙ, ПРОИЗВОАСТВЕННОЙ И ЭКОНОМИЧЕСКОЙ БЕЗОПАСНОСТИ РЕГИОНА
}

Аннотауия. Предмет. В статье оассматриваются проиессы становления иифровой экономики в регионах Џентрального федерального округа и их влияние на производственное развитие территорий. Методология. На основе использования статистического и сравнительного анализов производится оценка развития инновационных показателей субъектов ШФОО в сопоставлении с уровнем использования цифровых технологий. Результаты. Проведенное исследование показало, что в тех регионах, где более глубоко развиты инновационные проиессы, собственно, и внедрение иифровых технологий происходит более активно. Это говорит о том, что региональные администрации и представители бизнеса с большей заинтересованностью относятся $\kappa$ продвижению своих предприятий и территорий относительно развития инноващий и внедрению иифровых прочессов в производство и общественную деятельность. Область применения.

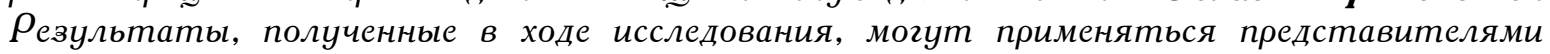
как органов государственной власти, так и бизнеса для анализа прочессов цифровизаиии на региональном уровне. Выводы. Проведенное исследование показало, что в тех регионах, где более глубоко развиты инноващионные прочессы, собственно, и внедрение цифровых технологий происходит более активно, что является залогом сохранения экономической безопасности. Данное обстоятельство свидетельствует о том, что региональные администоации и представители бизнеса с больщей заинтересованностью относятся к созданию условий безопасности и продвижению своих предприятий и территорий относительно развития инновачий и внедрению цифровых процессов в производство и общественную деятельность. При этом также нужно отметить, что в общероссийском разрезе, по данным справочника, НИУ ВШЭ «Центральный федеральный округ» занимает в основном первые места и только по 3 позиииям 2-е и 3 -е места по развитию иифровой экономики, а г. Москва, Московская, Белгородская, Тульская

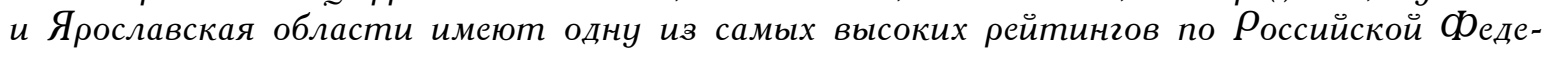
рачии.

Ключевые слова: иифровые технологии, инновационная ориентация, регион, экономический рост, производственная направленность, экономическая безопасность.

DONICHEV OLEG ALEXANDROVICH doctor of Economics, Professor, head of the Department "Economics and investment management and innovations " of Vladimir state University Alexander Grigoryevich and Nikolay Grigoryevich Stoletov, Vladimir, e-mail:donoa@vlsu.com 
GRACHEV SERGEY ALEXANDROVICH

Ph. D., associate Professor of "Economics and investment management and innovations " of Vladimir state University

Alexander Grigoryevich and Nikolay Grigoryevich Stoletov, Vladimir, e-mail: grachev-sa@yandex.ru

\title{
DIGITAL TECHNOLOGIES IN THE FORMATION OF INNOVATIVE, INDUSTRIAL AND ECONOMIC SECURITY OF THE REGION
}

\begin{abstract}
Object. The article discusses the processes of formation of the digital economy in the regions of the Central Federal district and their impact on the industrial develooment of the territories. Methodology. Based on the use of statistical and comparative analysis, the assessment of the development of innovative indicators of the subjects of the Central Federal district in comparison with the level of use of digital technologies is made. Results. The study showed that in those regions where innovation processes are more deeply developed, in fact, the introduction of digital technologies is more active. This suggests that regional administrations and business representatives are more interested in promoting their enterprises and territories with respect to the development of innovations and the introduction of digital processes in production and social activities. Apolication. The results obtained in the course of the study can be used by representatives of both public authorities and business to analyze the processes of digitalization at the regional level. Summary. The study showed that in those regions where innovation processes are more deeply developed, in fact, the introduction of digital technologies is more active, which is the key to maintaining economic security. This fact indicates that regional administrations and business representatives are more interested in creating security conditions and promoting their enterprises and territories with respect to the development of innovations and the introduction of digital processes in production and social activities. At the same time, it should also be noted that in the allRussian context, according to the Handbook, HSE "Central Federal district" occupies mainly the first places and only 3 positions 2nd and 3rd places for the development of the digital economy, and Moscow, Moscow, Belgorod, Tula and Yaroslavl regions have one of the highest ratings in the Russian Federation.
\end{abstract}

Keywords: digital technologies, innovative orientation, region, economic growth, production orientation, economic security.

Введение. Задача ускорения экономического роста национального народного хозяйства, преодоление рецессионных явлений в его развитии настоятельно требуют новых подходов к активизации общехозяйственных проявлений в жизни общества, уделения большего внимания реальному сектору экономики, закрепления значения в этой деятельности производственной ориентации регионов, что должно служить укреплению экономической безопасности страны в целом. Достижение этих величин возможно на основе инновационного обновления хозяйственной деятельности на базе активного использования цифровых технологий, способных в значительной мере ускорить производственный процесс.

Основная часть. Цифровые технологии целенаправленно внедряются в отраслях западной экономики и уже длительное время являются предметом исследования ученых.

В ряде первых научных публикаций в этой сфере были предложены концептуальные представления о природе цифровой экономики, что отмечалось как знания и информация, являющиеся ее ресурсами, оцифровка бизнес-процессов, виртуализация делового пространства, организационная скурпулезность, интеграция и межфирменная кооперация, системная инновационность и др. [16]

Подчеркивалась также фундаментальность предстоящей глобальной цифровизации, при которой будет иметь место высокоскоростное движение большого объема оцифрованной информации [17].

Значительное внимание было уделено исследованию влияния цифровых технологий на динамику развития промышленности. Анализировались противоречия, возникающие между практикой развития традиционных отраслей и новыми тенденциями, возникающими в результате цифровизации [18]. 
Было отмечено, что технологии Интернета привносят инновационные решения в отношения между производителями, продавцами и потребителями. Вопросы маркетинга и ценообразования на основе цифровых технологий приобретают значительный масштаб [19]. Были исследованы и обоснованы организационные изменения в промышленных компаниях, вызванные процессами цифровизации. При этом отмечалось значение и ценность программного обеспечения этой сферы, способность фирмы модернизировать свою продукцию и реализовывать ее в различных версиях [20].

Поэтому особое место занимал анализ динамики разработки программного обеспечения и его влияния на экономику. При этом отмечалось, что современные хозяйственные отношения трансформируются по большей части благодаря внедрению цифровых инноваций в производство [1].

Следует отметить, что проблемам внедрения и развития цифровых технологий в отечественной экономике стали больше внимания уделять российские исследователи. Они отмечают, что цифровая экономика затрагивает весь широкий спектр практических решений, касающихся управления как на уровне страны, так и на уровне компаний и их отдельных направлений деятельности. Специалисты ищут инструменты, которые позволят оптимизировать деятельность организаций с точки зрения их технологических процессов и скорости принятия решений [2].

Кроме того, в числе серьезных проблем, затрагивающих значительные слои населения и возникающих в результате развития цифровой экономики, находится вопрос: не приведет ли она к дальнейшему усилению экономического неравенства или будет способствовать его ослаблению, поскольку в условиях развертывания процессов цифровизации возрастает спрос на высококвалифицированный персонал [3].

Более того, стремительное развитие цифровых технологий приводит к трансформации экономических отношений. Такой ресурс, как данные, стал оказывать большое влияние на экономическое развитие и определять потенциал экономики [4].

При этом важно отметить, что развитие ряда сквозных цифровых технологий становится ключевым фактором роста национальной экономики, позволяющим обеспечить глобальную конкурентоспособность производственных компаний [5].

В условиях развития цифровой экономики и информационных технологий резко возрастает потребность, например, в так называемых сообществах провайдеров решений, которые должны содержать высокую квалификацию и базовые знания, опыт реализации производственных инновационных вопросов [6].

Но особое внимание в исследованиях уделяется проблемам обеспечения безопасности экономических систем.

Одними из важнейших элементов внедрения цифровых технологий являются «интеллектуальные системы учета», с помощью которых допустимо обеспечить возможность сбора, хранения, наблюдаемости и анализа передаваемой информации, а переход на цифровую базу позволит ускорить данный процесс. При этом компоненты системы, также как и приборы учета, в целях экономической безопасности должны создаваться именно российскими специалистами, что позволит использовать смешанный адаптивно-новаторский сценарий развития цифровых технологий [7].

Исходя из этого наука, образование, новые знания и основанные на них промышленные технологии становятся основным активом цифровой экономики и залогом обеспечения инновационной безопасности регионов [8].

Между тем информация, представляющая собой один из основных аспектов формирования нового знания, а также развития и управления деятельностью человека, становится определяющей и нуждается в сохранении. При такой взаимосвязи человека и информации необходимо в первую очередь руководствоваться ее количеством и достоверностью [9].

В то же время глобальные и региональные закономерности и тенденции развития научных и образовательных процессов свидетельствуют, что имеет место изменение окружающей их среды, связанное с ее цифровизацией, усиливается угроза рисков размывания границ надпрофессиональных и профессиональных компетенций [9].

Но в большей мере стоят проблемы обеспечения всех видов безопасности субъектов циф- 
ровой экономики. Например, высказывается озабоченность тем, что расширение цифрового сервиса и индивидуализации многих видов услуг повышает угрозу мошенничества при снижении контроля со стороны пользователей и провайдеров. Риски утечки информации требуют повышения уровня защиты электронных систем [10].

Кроме того, переход к цифровому обществу связан с необходимостью развития системных мер по эффективному встраиванию всей экономики в цифровую трансформацию. Поэтому целевая задача безопасности в этих условиях связана с построением экосистемы цифровой экономики - как партнерства организаций, взаимодействующих на основании имеющихся у них электронных платформ, аналитических интернет-систем [15].

В то же время с позиций обеспечения экономической безопасности государственного и корпоративного секторов и населения вызывает озабоченность наличие разрыва между уже сформированным цифровым потенциалом, включая доступ к Интернету, наличие мобильной 3G и 4G связи, уровнем использования компьютеров в быту и офисной работе, практически соответствующим лучшей мировой практике, и распространением электронного бизнеса, развитым существенно хуже [12].

Более того, в соответствии с требованиями обеспечения информационной и экономической безопасности в цифровой экономике кардинально меняются подходы к подготовке человеческого капитала. Любая эффективная деятельность непременно зависит от каждого отдельного человека, от анализа, его поведения, отношения к работе, его стимулов и мотивации, источников информации [13].

Таким образом, завершая теоретическую часть исследования, можно заключить, что цифровая экономика - это система экономических отношений между хозяйствующими субъектами, государством, а также объектами, которые способны генерировать, накапливать, обрабатывать и обмениваться информацией посредством частей информационнокоммуникационных технологий [14].

Теоретические исследования также показали, что состояние развития и внедрения цифровых технологий происходит неравномерно по регионам и во многом зависят от состояния общего инновационного развития территорий, при этом ориентация на производственное развитие региона является преобладающей и являющейся следствием его цифровой инновационной направленности.

Это важно, потому что основным производственным полигоном, на котором разворачиваются процессы внедрения цифровой экономики, являются региональные экономические системы и их промышленно-хозяйственный потенциал. Более того, по нашему мнению, основной гипотезой, которую необходимо исследовать, является тезис о том, что в тех регионах, в которых активно осуществляются инновационные преобразования, в реальном секторе отраслей народного хозяйства наиболее развиты и цифровые технологии. При этом для осуществления оценки вклада каждого региона в инновационное и цифровое развитие территорий произведем их ранжирование по отдельным показателям, взяв за критерий не абсолютные значения сравниваемых величин, а их ранги в показателях региона, что дает возможность получения наиболее достоверных значений. Сравнительный анализ будем производить на примере регионов ЦФО.

При этом нужно оговориться, что главной нашей задачей будет исследование процессов использования в производственной деятельности инноваций в целях создания условий для продвижения в регионах цифровых технологий и создания условий их экономической безопасности. В статистических сборниках имеется достаточно подробная информация использования всех видов инноваций. Поэтому мы и ставим задачу проанализировать, как взаимосвязаны между собой внедряемые инновации и состояние развития цифровой экономики.

Более того, мы должны подчеркнуть, что, анализируя показатели инновационной деятельности регионов ЦФО, мы отмечаем, что они в подавляющем большинстве имеют либо производственную, либо научную, но опосредованно связанную с реальным сектором экономики направленность. Это же в полной мере можно высказать и в отношении большинства показателей цифровой экономики. 
Таблица 1

Показатели инновационного развития регионов ЦФО, 2017 год.

\begin{tabular}{|c|c|c|c|c|c|c|c|c|c|c|c|c|c|c|c|c|}
\hline & $\begin{array}{c}\text { Числ. } \\
\text { пер. } \\
\text { связан., с } \\
\text { иссл. }\end{array}$ & $\begin{array}{l}\text { Ранг } \\
\text { ЦФО }\end{array}$ & \begin{tabular}{|c|} 
Внутр. \\
затр. на \\
иссл. и \\
разр., млн \\
руб. \\
\end{tabular} & $\begin{array}{l}\text { Ранг } \\
\text { ЦФО }\end{array}$ & \begin{tabular}{|} 
Иннов. \\
акт. орг.
\end{tabular} & $\begin{array}{l}\text { Ранг } \\
\text { ЦФО }\end{array}$ & $\begin{array}{c}\text { Объем } \\
\text { иннов. } \\
\text { товар., млн } \\
\text { руб. }\end{array}$ & $\begin{array}{l}\text { Ранг } \\
\text { ЦФО }\end{array}$ & \begin{tabular}{|c|} 
Затраты \\
на технол. \\
инн., млн \\
руб.
\end{tabular} & $\begin{array}{l}\text { Ранг } \\
\text { ЦФО }\end{array}$ & $\begin{array}{c}\text { Раз. } \\
\text { перед. } \\
\text { произв. } \\
\text { техн. }\end{array}$ & \begin{tabular}{|l|} 
Ранг \\
ЦФО
\end{tabular} & $\begin{array}{c}\text { Использ. } \\
\text { перед. } \\
\text { произ. } \\
\text { техн. }\end{array}$ & $\begin{array}{c}\text { Ранг } \\
\text { ЦФО }\end{array}$ & $\begin{array}{l}\text { Сумма } \\
\text { рангов }\end{array}$ & $\begin{array}{l}\text { Место } \\
\text { в } \\
\text { округе }\end{array}$ \\
\hline PQ & \begin{tabular}{|l|}
7077887 \\
\end{tabular} & - & 1019152,4 & - & 8,5 & - & 4166998,7 & - & 1404985,3 & - & 1402 & - & 240054 & - & & \\
\hline ЦФО & 362463 & - & 530212,2 & - & 9,9 & - & \begin{tabular}{|l|}
1119964,2 \\
\end{tabular} & - & 457472,1 & - & 480 & - & 77966 & - & & \\
\hline Белгородская & 1655 & 11 & 1921,1 & 10 & 14,8 & 2 & 101169, & 4 & 23852,4 & 4 & 37 & 4 & 2408 & 10 & 45 & 4 \\
\hline Брянская & 688 & 15 & 977,7 & 14 & 6,2 & 15 & 12198,6 & 10 & 1466,9 & $14-15$ & 16 & 8 & 1603 & $14-15$ & 91 & 14 \\
\hline Владимирская & 5365 & 6 & 5291,3 & 8 & 9,0 & \begin{tabular}{|l|}
$8-9$ \\
\end{tabular} & 34029,9 & 8 & 6077,6 & $12-13$ & 10 & 10 & 6728 & 3 & 56 & 8 \\
\hline Воронежская & 10654 & 3 & 8164,5 & 3 & 11,7 & 5 & 32481,8 & 12 & 13518,7 & $5-6$ & 26 & 6 & 2538 & 9 & 43,5 & 3 \\
\hline Ивановская & 574 & 16 & 585,7 & 16 & 4,2 & 17 & 219,2 & 18 & 253,3 & 18 & 23 & 7 & 933 & 18 & 104 & 16 \\
\hline Калужская & 9275 & 4 & 6070,9 & 5 & 9,0 & \begin{tabular}{|l|}
$8-9$ \\
\end{tabular} & 16574,3 & 16 & 10539,7 & 11 & 46 & 3 & 3176 & 6 & 53,5 & $6-7$ \\
\hline Костромская & 114 & 18 & 130,8 & 18 & 2,8 & 18 & 14590,9 & 5 & 559,6 & 17 & - & 18 & 1668 & 13 & 107 & 17 \\
\hline Курская & 2719 & 9 & 5936,1 & 7 & 5,0 & 16 & 30361,0 & 7 & 2061,0 & 16 & - & 18 & 1291 & 17 & 90 & 13 \\
\hline Липецкая & 530 & 17 & 291,1 & 17 & 18,5 & 1 & 63108,2 & 6 & 15321,4 & 8 & - & 18 & 3422 & 5 & 65 & 9 \\
\hline Московская & 86579 & 2 & 119715,9 & 2 & 8,9 & 10 & 384328,6 & 1 & 136250,6 & 1 & 101 & 2 & 16819 & 2 & 20 & 1 \\
\hline Орловская & 837 & 14 & 976,4 & 15 & 6,8 & 13 & 1428,8 & 17 & 1207,2 & $14-15$ & 2 & 13 & 1498 & 16 & 102 & 15 \\
\hline Рязанская & 2461 & 10 & 1594,4 & 12 & 12,1 & 4 & 19887,4 & 11 & 5585,9 & 9-10 & 7 & $11-12$ & 1603 & $14-15$ & 71,5 & 10 \\
\hline Смоленская & 903 & 13 & 1604,5 & 11 & 6,5 & 14 & 10137,5 & 13 & 4286,3 & $9-10$ & 12 & 9 & 1750 & 12 & 81,5 & 12 \\
\hline Тамбовская & 1125 & 12 & 1079,2 & 23 & 11,0 & 6 & 12962,6 & 9 & 5818,9 & 3 & - & 18 & 1933 & 11 & 72 & 11 \\
\hline Тверская & 3971 & 8 & 4644,3 & 9 & 8,7 & 11 & 10053,9 & 15 & 14569,0 & 2 & 7 & $\mid 11-12$ & 4206 & 4 & 141 & 18 \\
\hline Тульская & 4142 & 7 & 5974,9 & 6 & 9,2 & 7 & 80875,4 & 2 & 16119,8 & 7 & - & 18 & 2867 & 7 & 53,5 & $6-7$ \\
\hline Ярославская & 6354 & 5 & 6938,5 & 4 & 8,3 & 12 & 46557,6 & 3 & 5778,9 & $12-13$ & 29 & 5 & 2874 & 8 & 49,5 & 5 \\
\hline г. Москва & 224517 & 1 & 358214,8 & 1 & 14,3 & 3 & 248998,8 & 14 & 194205,0 & $5-6$ & 164 & 1 & 20649 & 1 & 26,5 & 2 \\
\hline
\end{tabular}

Источник: авторская разработка на основе «Регионы России. Социально-экономические показатели. - 2018. Cmam. cб./ Poccmam. - M., 2018. - 1162 c.

Таблица 2

\section{Основные показатели развития цифровой экономики в субъектах Российской Федерации: 2017*.}

\begin{tabular}{|c|c|c|c|c|c|c|c|c|c|c|c|c|c|c|c|c|}
\hline & \multicolumn{4}{|c|}{$\begin{array}{l}\text { Абонен. широкопол. дост. к ин- } \\
\text { терн. в расчете на } 100 \text { чел. (eд.) }\end{array}$} & \multicolumn{6}{|c|}{ Уд. вес нас., исп. интернет (проценты) } & \multicolumn{4}{|c|}{$\begin{array}{c}\text { Уд. вес орг., (в общем числе) } \\
\text { (процентыз): }\end{array}$} & \multirow[b]{2}{*}{$\left|\begin{array}{c}\text { Сумма } \\
\text { рангов по } \\
\text { округу }\end{array}\right|$} & \multirow[b]{2}{*}{$\begin{array}{l}\text { Место в } \\
\text { округе }\end{array}$} \\
\hline & $\begin{array}{l}\text { фиксиро- } \\
\text { ванного }\end{array}$ & \begin{tabular}{|l} 
ранг \\
ЦФО
\end{tabular} & $\begin{array}{c}\text { мобильно- } \\
\text { го }\end{array}$ & \begin{tabular}{|l|} 
ранг \\
ЦФО
\end{tabular} & $\begin{array}{l}\text { в общ. } \\
\text { числ. } \\
\text { насел. }\end{array}$ & $\begin{array}{l}\text { ранг } \\
Ц Ф О\end{array}$ & \begin{tabular}{|c|} 
для \\
заказа \\
товаров, \\
услуг
\end{tabular} & $\begin{array}{l}\text { ранг } \\
\text { ЦФО }\end{array}$ & \begin{tabular}{|} 
для получе- \\
ния гос. \\
элект. услуг
\end{tabular} & $\begin{array}{l}\text { ранг } \\
\text { ЦФО }\end{array}$ & $\begin{array}{l}\text { Широко- } \\
\text { полосный } \\
\text { интернет }\end{array}$ & $\begin{array}{l}\text { ранг } \\
\text { ЦФО }\end{array}$ & $\begin{array}{l}\text { «облачные } \\
\text { сервисы» }\end{array}$ & $\begin{array}{l}\text { ранг } \\
\text { ЦФО }\end{array}$ & & \\
\hline PФ & 20,9 & - & 79,2 & - & 83,7 & - & 29,1 & - & 64,3 & - & 80,5 & - & 20,5 & - & & \\
\hline ЦФО & 24,6 & - & 92,8 & - & 86,2 & - & 33,5 & - & 71,3 & - & 85,6 & - & 23,2 & - & & \\
\hline Белгородская & 19,2 & 13 & 69,5 & 10 & 79,0 & 13 & 41,1 & 2 & 69,2 & $7-8$ & 87,7 & 6 & 24,8 & 3 & 54,5 & 5 \\
\hline Брянская & 15,8 & 17 & 66,1 & 16 & 77,8 & 15 & 21,4 & 15 & 54,4 & 15 & 87,6 & 7 & 13,7 & 17 & 102 & 18 \\
\hline Владимирская & 19,7 & 11 & 68,1 & 13 & 79,2 & 12 & 28,3 & 7 & 70,0 & 5 & 88,1 & 5 & 18,1 & 15 & 68 & 11 \\
\hline Воронежская & 23,9 & 4 & 68,7 & 11 & 80,6 & 9 & 16,7 & 16 & 67,6 & 9 & 86,9 & 8 & 23.1 & 4 & 61 & 8 \\
\hline Ивановская & 18,4 & $14-15$ & 68,2 & 12 & 84,5 & 5 & 33,1 & 4 & 64,8 & 11 & 84,7 & 11 & 20,2 & 12 & 69,5 & $12-13$ \\
\hline Калужская & 24,8 & 3 & 81,5 & 3 & 76,5 & 16 & 16,2 & 17 & 66,6 & 10 & 86,6 & 9 & 25,0 & 2 & 60 & 7 \\
\hline Костромская & 20,8 & 8 & 67,2 & 15 & 78,4 & 14 & 26,7 & 9 & 37,0 & 18 & 73,1 & 18 & 11,6 & 18 & 100 & 17 \\
\hline Курская & 28,3 & 2 & 72,1 & 8 & 83,2 & 6 & 32,1 & 5 & 62,6 & 13 & 82,1 & 14 & 21,6 & 8 & 56 & 6 \\
\hline Липецкая & 18,1 & 16 & 65,7 & 17 & 85,0 & 4 & 24,5 & 11 & 71,8 & 4 & 89,5 & 4 & 20,4 & 11 & 67 & $9-10$ \\
\hline Московская & 19,6 & 12 & $114,1^{* *}$ & $1-2$ & 92,8 & 1 & 37,8 & 3 & 86,2 & 1 & 80,6 & 16 & 21,4 & 9 & 43,5 & 2 \\
\hline Орловская & 20,2 & 10 & 71,8 & 9 & 71,7 & 18 & 22,1 & 14 & 43,3 & 16 & 84,3 & 12 & 20,02 & 13 & 92 & 15 \\
\hline Рязанская & 23,5 & 5-6 & 67,5 & 14 & 72,9 & 17 & 14,4 & 18 & 54,5 & 14 & 90,0 & 2 & 19,9 & 14 & 84,5 & 14 \\
\hline Смоленская & 21,3 & 9 & 63,0 & 18 & 80,2 & 10 & 26,9 & 8 & 75,2 & 2 & 86,3 & 10 & 21,3 & 10 & 67 & $9-10$ \\
\hline Тамбовская & 18,4 & $14-15$ & 78,2 & 4 & 81,7 & 8 & 23,5 & 12 & 63,9 & 12 & 82,6 & 13 & 22,1 & 6 & 69,5 & $12-13$ \\
\hline Тверская & 14,1 & 18 & 75,0 & $5-6$ & 82,4 & 7 & 23,4 & 13 & 40,0 & 17 & 71,7 & 17 & 16,2 & 16 & 93,5 & 16 \\
\hline Тульская & 23,1 & 7 & 75,0 & $5-6$ & 85,8 & 3 & 30,1 & 6 & 75,0 & 3 & 81,6 & 15 & 21,8 & 7 & 46,5 & 3 \\
\hline Ярославская & 23,5 & $5-6$ & 73,9 & 7 & 79,4 & 11 & 24,7 & 10 & 69,2 & $7-8$ & 89,6 & 3 & 22,9 & 5 & 49 & 4 \\
\hline г. Москва & 33,1 & 1 & $114,1 * *$ & $1-2$ & 91,3 & 2 & 43,4 & 1 & 69,7 & 6 & 95,2 & 1 & 33,2 & 1 & 13,5 & 1 \\
\hline
\end{tabular}

Источник: авторская разработка на основе «Индикаторы ичфровой экономики 2018 года». Статистический сборник НИУ. ВШЭ, 2018. 
В таблице 1 представлены 7 показателей инновационного развития регионов ЦФО в 2017 году. Соответственно, в таблице 2 выделены 7 индикаторов использования цифровых технологий в этих регионах также за 2017 год, сравнивая их, мы можем отметить, что в составе первых пяти территорий находятся Московская область, г. Москва, Воронежская, Белгородская и Ярославская области. Далее следуют Тульская и Калужская, Владимирская, Липецкая и Рязанская области. И на самых последних местах расположены Ивановская, Костромская и Тверская области.

Из таблицы 2 следует, что в ней ведущие места занимают г. Москва, Московская область, а также Тульская, Ярославская и Белгородская области. Далее следуют Курская, Калужская, Воронежская, Липецкая и Смоленская области. Аутсайдерами по этим показателям опять являются Тверская, Костромская области, и к ним добавляется Брянская область.

Заключение. Таким образом, проведенное исследование показало, что в тех регионах, где более глубоко развиты инновационные процессы, собственно, и внедрение цифровых технологий происходит более активно, что является залогом сохранения экономической безопасности. Данное обстоятельство свидетельствует о том, что региональные администрации и представители бизнеса с большей заинтересованностью относятся к созданию условий безопасности и продвижению своих предприятий и территорий относительно развития инноваций и внедрению цифровых процессов в производство и общественную деятельность. При этом также нужно отметить, что в общероссийском разрезе, по данным справочника, НИУ ВШЭ «Центральный федеральный округ» занимает в основном первые и только по 3 позициям 2-е и 3-е места по развитию цифровой экономики, а г. Москва, Московская, Белгородская, Тульская и Ярославская области имеют одну из самых высоких рейтингов по Российской Федерации.

Литература

1. Архипова О. В., Михайлова Е. В. Использование информационных систем для эффективного управления образовательным процессом в техническом вузе // Инновациии. - 2014. - № 6. - С. 92-95.

2. Белоусов Д. Р., Пенухина Е. А. О построении качественной модели российской экосистемы ИКТ // Проблемы прогнозирования. - 2018. - № 1. - С. 94-104.

3. Голова И. М., Суховей И. М. Вызовы инновачионной безопасности регионального развития в условиях цифрового общества // Экономика региона. - 2018. - T. 14, - выл. 3. - С. 987-1002.

4. Денисов А. Ф., Кардаш Д. С. Анализ практик применения ичифровых технологий в отборе персонала // Экономика и управление. - 2018. - №6. - С. 26-37.

5. Дьяченко О. В. Дефиниция категории «Цифровая экономика в зарубежной и отечественной науке // Экономическое возрождение России. - 2019. - № 1. - С. 86-98

6. Лукша О. П., Наталенко А. А., Пилонов Г. Б., Яновский А. Э. Поиск научно-технических компетенций и использование методик интеллектуального анализа текстов для формирования провайдеров решений в сфере открытых инновачий // Инновации. - 2018. - № 1. - С. 81-94.

7. Пименов В. В., Шафранский Л. К. Экономическая и информаџионная безопасность в условиях ичифровой трансформации: инструменты и механизмы по их нейтрализации // Экономическая безопасность и качество. - 2018. - № 1. - С. 25-30.

8. Попов Е. В., Семячков К. А. Инструментарий развития цифровых технологий в государственном секторе // Региональная экономика: теория и практика. - 2018. - T. 16. - № 7. - C. 1320-1337.

9. Посталюк М. П., Посталюк Т. М. Цифровизаџия локальных систем региональной российской экономики: потребности, возможности и риски // Проблемы современной экономики. - 2018. - № 2. - С. 174 -177 .

10. Ремизова Т. С., Кошелева Д. Б. Применение ичифровых технологий для модернизации инфраструктуры энергетической отрасли России // Проблемы современной экономики. - 2018. - № 2. - C. 31-34.

11. Рихтер К. К., Пахомова Н. В. Цифровая экономика как инновация ХХІ века: вызовы и шансы для устойчивого развития // Проблемы современной экономики. - 2018. - № 2. - С. 22-30.

12. Стариков Е. Н., Раменская Л. А. Формирование изифровой экономики Свердловской области: предпосылки, тренды, направления технологического развития // Региональная экономика: теория и практика. - 2018. - T. 16. - № 8. - C. 1429-1444.

13. Удалов Д. В. Угрозы и вызовы ичифровой экономики // Экономическая безопасность и качество. 2018. - № 1. - C. 12-17.

14. Яковлев А. А. Новая экономика: подходы к определению // Проблемы современной экономики. 2018. - № 2. - C. 34-38.

15. Cristensen V., Maskell P. The Industrial dynamics of the new digital economy. Edward Publishing ltd. 2003. $271 \mathrm{p}$.

16. Illing G., Peitz M. Industrial Organization and the Digital Economy. London: The MIT Press. 2006. 308 p.

17. Kehal H., Singh V. Digital Economy: Impacts, Influences and Challenges. IGT Global. 2004. 352 p.

18. Maletcki E., Moriset B. The digital economy: Business organization, production processes and regional developments. New York: Routledge. 2008. 296 p.

19. Negroponte N. Being Digital. New York: Knopf. 1995. 256 p. 
20. Tapscott D. The Digital Economy: Promise and Peril in the Age of Networked Intelligence. New York: McGrow-Hill. 1997. 288 p.

\section{References:}

1. Arhipova $O$. V., Mihajlova E. V. Ispol'zovanie informacionnyh sistem dlya effektivnogo upravleniya obrazovatel'nym processom v tekhnicheskom vuze // Innovacii. - 2014. - № 6. - S. 92-95.

2. Belousov D. R., Penuhina E. A. O postroenii kachestvennoj modeli rossijskoj ekosistemy IKT // Problemy prognozirovaniya. - 2018. - № 1. - S. 94-104.

3. Golova I. M., Suhovej I. M. Vyzovy innovacionnoj bezopasnosti regional'nogo razvitiya $v$ usloviyah cifrovogo obshchestva // Ekonomika regiona. - 2018. - T. 14, - vyp. 3. - S. 987-1002.

4. Denisov A. F., Kardash D. S. Analiz praktik primeneniya cifrovyh tekhnologij v otbore personala // Ekonomika i upravlenie. - 2018. - №6. - S. 26-37.

5. D'yachenko O. V. Definiciya kategorii "Cifrovaya ekonomika v zarubezhnoj $i$ otechestvennoj nauke // Ekonomicheskoe vozrozhdenie Rossii. - 2019. - № 1. - S. 86-98.

6. Luksha O. P., Natalenko A. A., Pilonov G. B., YAnovskij A. E. Poisk nauchno-tekhnicheskih kompetencij $i$ ispol'zovanie metodik intellektual'nogo analiza tekstov dlya formirovaniya provajderov reshenij $v$ sfere otkrytyh innovacij // Innovacii. - 2018. - № 1. - S. 81-94.

7. Pimenov V. V., SHafranskij L. K. Ekonomicheskaya i informacionnaya bezopasnost'v usloviyah cifrovoj transformacii: instrumenty $i$ mekhanizmy po ih nejtralizacii // Ekonomicheskaya bezopasnost' $i$ kachestvo. 2018. - № 1. - S. 25-30.

8. Popov E. V., Semyachkov K. A. Instrumentarij razvitiya cifrovyh tekhnologij v gosudarstvennom sektore // Regional'naya ekonomika: teoriya i praktika. - 2018. - T. 16. - № 7. - S. 1320-1337.

9. Postalyuk M. P., Postalyuk T. M. Cifrovizaciya lokal'nyh sistem regional'noj rossijskoj ekonomiki: potrebnosti, vozmozhnosti i riski // Problemy sovremennoj ekonomiki. - 2018. - № 2. - S. 174-177.

10. Remizova T. S., Kosheleva D. B. Primenenie cifrovyh tekhnologij dlya modernizacii infrastruktury energeticheskoj otrasli Rossii // Problemy sovremennoj ekonomiki. - 2018. - № 2. - S. 31-34.

11. Rihter K. K., Pahomova N. V. Cifrovaya ekonomika kak innovaciya XXI veka: vyzovy i shansy dlya ustojchivogo razvitiya // Problemy sovremennoj ekonomiki. - 2018. - № 2. - S. 22-30.

12. Starikov E. N., Ramenskaya L. A. Formirovanie cifrovoj ekonomiki Sverdlovskoj oblasti: predposylki, trendy, napravleniya tekhnologicheskogo razvitiya // Regional'naya ekonomika: teoriya i praktika. - 2018. - T. 16. - № 8. - S. 1429-1444.

13. Udalov D. V. Ugrozy i vyzovy cifrovoj ekonomiki // Ekonomicheskaya bezopasnost' i kachestvo. - 2018. № 1. - S. 12-17.

14. YAkovlev A. A. Novaya ekonomika: podhody k opredeleniyu // Problemy sovremennoj ekonomiki. - 2018. № 2. - S. 34-38.

15. Sristensen V., Maskell P. The Industrial dynamics of the new digital economy. Edward Publishing ltd. 2003. $271 \mathrm{p}$.

16. Illing G., Peitz M. Industrial Organization and the Digital Economy. London: The MIT Press. 2006. 308 p.

17. Kehal H., Singh V. Digital Economy: Impacts, Influences and Challenges. IGT Global. 2004. 352 .

18. Maletcki E., Moriset B. The digital economy: Business organization, production processes and regional developments. New York: Routledge. 2008. 296 p.

19. Negroponte N. Being Digital. New York: Knopf. 1995. 256 p.

20. Tapscott D. The Digital Economy: Promise and Peril in the Age of Networked Intelligence. New York: McGrow-Hill. 1997. 288 p. 